\title{
CONSTITUIÇÃO, DISCURSO JURÍDICO-PENAL E ARGUMENTAÇÃO: A BUSCA PELA REDUÇÃO DAS INCONGRUÊNCIAS PUNITIVAS.
}

\author{
CONSTITUTION, CRIMINAL AND ADDRESS LEGAL ARGUMENT: THE QUEST FOR \\ REDUCING PUNITIVE INCONSISTENCIES.
}

\section{Resumo}

A crise do sistema criminal é comentada por estudiosos há algumas décadas, indicando que ciências jurídico-penais não cumprem seu papel dado pelo ordenamento e Constituição nem o esperado pela sociedade. Neste passo, buscando a construção de sociedade calcada nos princípios fundamentais da Carta Maior e com promoção do bem estar social, utiliza-se de análise das teorias da argumentação e do discurso jurídico para propor soltura das amarras estritamente legalistas na fundamentação e aplicação do direito neste ramo que lida com bens mais valiosos do plexo axiológico da Constituição Federal, baseando-se em ética e valores e não na defesa do sistema jurídico a todo preço, num funcionalismo sistêmico autoreferenciado, que desconsidera realidade posta e a crítica ao próprio direito legislado.

Palavras-Chave: Constituição Federal; Sistema penal; Discurso jurídico; Argumentação jurídica.

\begin{abstract}
The crisis in the criminal justice system is commented by experts for several decades, indicating that criminal sciences do not fulfill their role given by law and Constitution nor expected by society. Thus, seeking the construction of society grounded in the fundamental principles of the Constitution and promoting social welfare, is utilized the analysis of the theories of argumentation and legal discourse to propose loosening the shackles on legalistic reasoning and application of the law in this branch that deals with the most valuable axiological assets of the Federal Constitution, based on ethics and values and not in defense of the legal system at all costs, in a self-refered systemic functionalism that ignores both the reality as criticism of the right.
\end{abstract}


Keywords: Constitution; Criminal System; Legal Discourse; Legal Argumentation.

\section{INTRODUÇÃO}

A sociedade brasileira tem sua tessitura social e jurídica abalada com os graves problemas penais que atingem a população, com correlatos déficits de segurança pública, de punições adequadas e de manejo de uma justiça penal justa e eficiente.

Dessa forma, restam ameaçados princípios fundamentais da nossa Constituição Federal, como objetivo de construção de sociedade livre, justa e solidária com promoção do bem de todos sem preconceitos ou discriminações, desenvolvimento nacional e dignidade da pessoa humana.

Então, no desiderato de minorar distorções no sistema penal e promover bem estar social nesta área, acreditamos ser a argumentação e o discurso jurídicos vias de acesso a formas mais justas e ideais de manejo de sistema criminal, com correlata interpretação jurídica.

A fundamentação e aplicação do direito mais consentâneo com Constituição, realidade posta, valores e ética tem papel fundamental na diminuição de incongruências punitivas e distorções graves do sistema penal.

Neste desiderato, reforçamos papel das teorias da argumentação e discurso jurídico com a sua abertura necessária para lidar com tal tema sem perder de vista a interação do mundo jurídico com necessidades sociais, realidade, valores e considerações à pessoa.

\section{ARGUMENTAÇÃO JURÍDICA}

Uma importante guinada no estudo do Direito nas últimas décadas se deu a partir do estudo da argumentação jurídica. Em grande parte, isto se deve à crise da modernidade e do positivismo no Direito como padrão de racionalidade extremo com excessivo apego à lei por ser construção racional, aplicável a toda universalidade em qualquer tempo e, assim, referência de justiça como observa Soares (2008, p. 71).

Estas características vieram a se mostrar conservadoras e legitimavam classe 
dominante pela manutenção de status quo. A falência das promessas da modernidade como liberdade, igualdade, progresso e felicidade franqueadas a todos, além da razão tecnocrática que põe saber a serviço do poder e tentativas de apoderação do discurso, ensejaram perspectiva pós-moderna (SOARES, 2008, p. 74), e também pós-positivismo.

A teoria da argumentação como forma discursiva de apresentação do Direito e da resolução dos casos analisados por ele tem muito a contribuir para busca de soluções justas, análise e interpretação do Direito e dos fatos.

O conhecimento científico, seus métodos e filosofia são úteis e necessários à busca do direito mais adequado a uma situação concreta ou teórica e complementam o uso da argumentação, quer em sua composição estrutural e procedimental - teoria da argumentação, quer nos argumentos e raciocínios imediatos.

O Direito e a Filosofia também têm destaque na interação com o senso comum, na busca de acordo social e com vistas a uma sociedade aberta dos intérpretes, com mais legitimação por participação popular, para formar espírito crítico e conhecimento informado, diminuindo distância entre conhecimento científico e senso comum, entre razões estudadas e especulações com bases falsas ou com esteio em mitos.

Em paralelo, a forma argumentativa do Direito é meio fértil para se desenvolver busca de solução jurídica mais adequada, pois propicia discussões, apresentação de argumentos e racionalidades das partes, exposição a público de razões e submissão a críticas.

$\mathrm{Na}$ argumentação, meio inescapável ao Direito, atuam formas, como retórica, e conteúdos, sejam eles jurídicos, filosóficos, sociais ou demais conhecimentos, que devem embasar uma solução consentânea com contexto social, valores e a considerar expectativas da sociedade, o senso comum informado.

Assim, na busca de um conhecimento total sobre assunto no qual o Direito é chamado a solucionar, a argumentação jurídica não será sempre completa e ideal quando faltarem considerações acerca de conhecimento científico e de senso comum e sua busca pela participação popular, seja diretamente ou por considerações do contexto social.

Em sua teoria da argumentação, vê Günther (2011) duas atividades na justificação das normas, quais sejam, mostrar razões para aceitá-la ou relacioná-la a situação prática verificando sua adequação.

Para o autor, o princípio de universalização de Habermas (consequências aceitas por todos, que resultem do cumprimento geral e da satisfação de cada um, preferidas a de outras normas) considera num mesmo momento aplicação e fundamentação de normas. Todavia, não há confundir aplicação de princípio moral com aplicação de norma que pode fundamentar-se 
nesse. Para Günther, em qualquer caso "um princípio de fundamentação, sem referência a situações de aplicação, per si seria uma fórmula vazia" (GÜNTHER, 2011, p. 10).

Ao afirmar a especialização dos discursos na fundamentação de pretensões de validade, Günther (2011, p. 23) propõe um princípio que universalize determinada regra a todos, chamando-o de " $U$ " 1 . O princípio "U" em discursos práticos assume função de regra de argumentação, para gerar juízo imparcial acerca de validade da norma, que vem da concordância das razões de justificação da norma.

Para ele, a dificuldade, senão impossibilidade de colocar-se no lugar do outro, da alteridade, para visualização de uma norma moral a ser universalizável confluiu para uma aceitação de cada um conjuntamente das normas, considerando a existência do outro, o que levaria ao correspondente interesse comum.

O autor sustenta que o princípio de universalização, "U”, se daria por confluência de interesses e aceitação de suas consequências, até porque de outra forma não se apuraria o interesse comum quando fosse observada uma regra.

Entretanto, a aplicação em todas as situações pressupõe casos iguais em que a norma possa ser aplicada. Em outro contexto poderá ter a norma consequências diferentes.

O pensamento por consequências para a validade de uma norma por aplicação de "U” é importante para a aceitação por todos da norma, porém a adequação da norma a todas as situações e consequências existentes quando da sua aplicação não é viável, então a norma será sempre parcial, nunca completa e nunca de aplicação a todas as situação e consequências que sejam possíveis.

Adita-se que o princípio "U” é dialógico, pois todos devem considerar a posição do outro para "dimensionar intensidade de todos os interesses afetados" (GÜNTHER, 2011, p. 27), assim o juízo de imparcialidade seria cumprido.

Destarte, para Günther, os participantes do discurso buscam verdade a partir de processo argumentativo. O princípio "U" é transformado em princípio ético do discurso $\mathrm{D}$, "segundo o qual uma norma só será válida, quando cada uma a aceitar (ou possa aceitá-la) como participante de um discurso prático" (2011, p. 36).

Ainda para este autor, o discurso de aplicação da norma combina sua pretensão de validade com o contexto apresentado, dentro do qual a norma é aplicada. Por outro lado, já discursos de fundamentação devem fazer a dinâmica da aplicação parar e generalizar uma

\footnotetext{
${ }^{1}$ Em Günther (2011, p. 23): “O princípio de universalização ' $U$ ' desempenha o papel de uma regra de argumentação que deve proporcionar a passagem de evidências empíricas, a respeito das consequências e dos efeitos colaterais de uma aplicação geral da norma sobre as necessidades de cada um individualmente, para a norma que representa em si um interesse geral".
} 
determinada norma e sua aceitação por todos.

Na aplicação do Direito, na construção de Günther, não se trata ainda da análise de interesses generalizáveis e particulares, o que fica para a fundamentação, mas sim de uma interpretação que: “à luz de todos os sinais característicos de uma situação, seja coerente" (2011, p. 63).

Importa ressaltar, todavia, que ao se tratar seja de fundamentação ou de aplicação do Direito, estamos em plena atividade argumentativa e discursiva, com as características aqui traçadas que compõem um processo de oportunidades de produção de argumentos, conjecturas e discussão, através da estrutura normativa posta.

Assim, cremos ser a argumentação inerente e indissociável do Direito, tanto na fundamentação do Direito e levantamento de premissas racionais que embasem um posicionamento, quanto na aplicação em si do Direito ao caso, oportunizando controle e crítica da decisão judicial posta.

Estamos com aqueles que acreditam que a argumentação é também forma de realização do Estado de Direito, já que possibilita postulação e defesa frente ao Estado e particulares e apontamento de inconsistências e despropósitos nas decisões judiciais, ordenamento jurídico em si e na estrutura judicial, política e de poder do Estado. Neste sentido, MacCormick (2008, p. 42) sustenta tanto a compatibilidade entre segurança jurídica e argumentação quanto uma relação de imbricação e necessidade recíproca ${ }^{2}$ entre eles.

Não são contraditórios a argumentação e o Estado de Direito, pois a certeza não é o único valor presente no Estado. Além de ser a certeza, defeasible, ou seja, excepcionável, provisória, o que comunga com o caráter argumentativo do Direito.

Outrossim, podemos dizer que a argumentação pela via do discurso jurídico exige complementação, por ser via apenas procedimental de se chegar a uma decisão jurídica mais acertada, uma aplicação mais próxima da justiça.

De forma que se chega a conclusões no Direito por verossimilhança, pois ele é argumentativo, mas não é puro decisionismo. Está aberto a crítica, a construção mais racional e, por isso, a controle jurídico e social.

A argumentação jurídica, com base em textura aberta do Direito, permeável a contexto histórico-social, valores e senso-comum, com sua busca de integração dos

\footnotetext{
Segundo MacCormick (2008, p. 42): "Há um risco de mal compreender o 'Estado de Direito' como ideal se o tomamos isoladamente. Quando o fazemos, nós talvez ressaltemos seus aspectos mais estáticos, que prometem certeza jurídica e segurança de expectativas jurídicas. Mas o mesmo ideal possui um aspecto dinâmico também, ilustrado pelo direito de defesa e pela importância de deixar tudo aquilo que é contestável ser contestado".
} 
indivíduos no ordenamento jurídico e, por caminho inverso, legitimação das normas com base em consideração da aceitação social de essencial representatividade e adequação delas, está ainda sujeita a críticas pertinentes.

Isto porque, como meio, o método de fundamentação e aplicação do Direito pode ser utilizado a talante de quem detenha o poder de aplicação. No entanto, é justamente a busca do conhecimento, reflexão sobre regras, princípios e fins constitucionais e filosofia que podem enriquecer esse meio, a argumentação jurídica, de forma a pautar sua atuação em critérios de legitimidade, racionalidade e representatividade.

Nunca se chegou definitivamente a forma justa de se produzir soluções jurídicas mais adequadas, até porque isto deveria derivar desde produção jurídica até sua aplicação consentânea com contexto e valores sociais e máxima representatividade e acordo do povo na decisão. Esta impossibilidade decorre de caráter evolutivo da sociedade e Estado, onde devir é constante.

A argumentação e discurso jurídicos se adequam a uma busca dessas soluções adequadas pois estão sempre abertos a discussão e problematização, utilizando-se de racionalidade dos envolvidos e forma aberta de demonstração da verossimilhança de suas conclusões. Em que pese não deverem ser utilizados como meio de legitimação impositiva, mas com considerações de conteúdo, traçados por métodos e filosofia do conhecimento e através de contextualizações sociais e valorativas imanentes ao Direito.

De modo que, para uma solução de conflito mais adequada, deve-se expor objetivamente os critérios em que se baseia, tanto para controle de instâncias mais elevadas, quanto para o senso comum poder adaptar-se, rejeitá-los ou haver conformação, gerando pressão social, amplo debate em uma sociedade aberta, proporcionando integração social ou institucional aos argumentos, interesses e conclusões chegadas.

\section{DISCURSO JURÍDICO NO DIREITO PENAL E SUA CRISE DE LEGITIMIDADE}

Tal forma de se chegar à solução mais adequada se dá, com mais importância ainda, no âmbito punitivo e sistema penal, por lidarem com direitos fundamentais como liberdade e até a vida.

No entanto, por diversos problemas práticos e de aplicação e fundamentação do direito, o sistema penal encontra-se em crise, em que pese a produção dogmática acentuada 
neste ramo.

De fato, dentre as ausências mais sentidas no ramo penal, que viriam a acentuar sua legitimidade, aceitação e busca por resultados efetivos, estão a problematização do conhecimento na área e abertura à discussão, integração da sociedade aos conhecimentos e problemas estabelecidos na busca de soluções consensuais e informadas ao molde do póspositivismo, de democracia participativa e das teorias da argumentação.

A seara punitiva do Estado carece de atuação legislativa, executiva e judiciária para fazer aplicação mais adequada de seus instrumentos e possibilitar amplo desenvolvimento e mínima restrição a Direitos Fundamentais, que correspondem atualmente a valor de destaque no plexo valorativo dos ordenamentos jurídicos da tradição romano-germânica, como se vê no Direito brasileiro.

A forma punitiva mais incisiva do Estado, o sistema penal, encontra-se em crise de legitimidade já de longa data estudada, entretanto, poucas alterações vieram a mudar esse quadro, como observado pela Criminologia e Sociologia.

O discurso estatal da punição no Direito Penal diverge da realidade da sua aplicação e dos meios empregados para sua consecução. Faltam instrumentos alternativos e flexíveis a serem postos a serviço da sanção estatal para consecução de seu fïm de direcionamento social de forma a evitar condutas danosas à sociedade.

No campo do Direito Penal, o discurso jurídico está mais restrito por princípio da legalidade e princípios de proteção do ser humano do alvedrio punitivo do Estado, o que não inviabiliza de nenhum modo a interferência das partes na resolução do conflito, o caráter argumentativo, a aplicação e sopesamento de princípios e a interpretação. Ao inverso, essas características são potencializadas para busca de justiça.

De todo modo, a atuação político-legislativa, com escolhas e proposições de políticas criminais adequadas ao texto constitucional e realidade posta, no contexto da legalidade mais incisiva no sistema penal é também ponto chave para a adequação da punição estatal a seus fins e fundamentos.

Resulta-se, então, que, como parte da falência das promessas da pós-modernidade, podemos incluir o sistema penal e sua pretensa racionalidade. Assim, Foucault (1987, p. 239) crê, frente ao fracasso de mais de 150 anos da prisão, que ela na verdade tenha serventia, tenha outras finalidades que não as ditas, já que frente a estas já se sabe que nada faz ou até piora o quadro.

Em sua hipótese, o sistema prisional serve como gestão diferencial de ilegalidades, há uma estratégia global das ilegalidades na qual o castigo está inserido e o fracasso da prisão 
pode ser compreendido a partir daí.

Tal análise se dá a partir de elementos da realidade punitiva, uma vez que a legislação e discurso jurídico-penal não vislumbram nem admitem os reais efeitos ocasionados, e pouco se posicionam frente a eles.

É como se poder de fato atuasse via sistema punitivo por aceitação e favorecimento de seus resultados, uma vez que o direito e seus atores, como Legislativo, Judiciário, Executivo, juristas e sociedade em geral pouco fazem para deter ilegalidades ínsitas, desvios de finalidade e realidade punitiva prática abertamente vista (e, paradoxalmente, por poucas vezes alardeada nos meios de comunicação de massa).

Em pensamento aproximado, Zaffaroni (1991, p. 15) afirma que não se poderia usar a palavra crise entre discurso jurídico-penal e sua realidade operacional, uma vez que os paradoxos estabelecidos entre eles são estruturais, nasceram e se desenvolveram juntos e nunca foram solucionados, ao menos na América Latina.

Acredita que a crise no sistema penal seja a evidência sabida por todos desse descompasso, tanto da nulidade ou negatividade dos resultados esperados ou pretendidos, da falsidade das premissas e dos meios ineficazes e insidiosos.

Nesse contexto, o direito não pode ficar inerte. Tal conclusão, em situação próxima, chegou-se quando do fim da $2^{\text {a }}$ Guerra e a perplexidade acerca das barbaridades cometidas sob império da legalidade ou de sua obscuridade.

Inclusive, ao tratar de algumas das respostas dadas face à deslegitimação do sistema penal, Zaffaroni cita a forma de eximir-se da incumbência da legitimação geral do sistema penal, assumindo papel apenas de cumpridor de ordens ou de legislação, à exemplo das frequentes respostas dadas em Nuremberg (ZAFFARONI, 1991, p. 83), numa ligação entre a omissão frente a um sistema penal perverso com regime nazista.

Haja vista que legalidade não é legitimidade, nem o sistema punitivo detém formas de atuar que podem ultrapassar considerações valorativas, de aplicação do direito e de sua máxima referência à Constituição e princípios como direitos humanos e fundamentais, o sistema penal está à disposição dos intérpretes e operadores do direito, que são compostos de toda a sociedade, além das instâncias de poder, para sua alteração ampla, reconstrução e estabelecimento de novos marcos do que é punível e como se dará a sanção.

Isto, afirme-se, sem alterar sistema legal posto e mesmo à sua revelia com declaração de inconstitucionalidades, uma vez que não pode se adequar à realidade, que o ilegitimou na esfera penal, subvertendo princípios e regras, como veremos adiante.

Afinal o que é a inconstitucionalidade progressiva, como a decisão de situações em 
trânsito para a inconstitucionalidade, com declaração de normas "ainda" constitucionais ou “já” inconstitucionais, senão a análise da realidade frente à fundamentação ou aplicação da norma?

No caso do sistema penal especificamente prisional, este nunca funcionou, no entanto, como a política criminal somente tem efeitos no plano da realidade, deve-se esperar prazo para verificação empírica de seus resultados, o que é feito por Criminologia.

Ocorre, então, que a ciência global do direito penal já está de longa data sabedora da pouca eficácia da ampla maioria de suas prescrições, fato este que deveria ter motivado novas proposições, o que ocorreu apenas em pequena medida, e em geral, retomando mesma (ir)racionalidade que baseou o programa criminal desde o início como: maior repressão à condutas consideradas criminosas, mais condutas a serem tidas como delituais, abarcamento completo pelo Estado de todo o procedimento, endurecimento de penas, exclusão dos direitos da vítima do processo criminal e sua objetivação, dentre outros.

\section{INCOMPATIBILIDADE DA REALIDADE DO SISTEMA PENAL FRENTE AO OBJETIVO CONSTITUCIONAL DE CONSTRUÇÃO DE SOCIEDADE JUSTA E PROMOÇÃO DE BEM ESTAR SOCIAL}

Ao tratar de instâncias formais de controle no sistema da justiça penal, Dias e Andrade (1997, p. 365) trazem realidade contundente estudada na perspectiva interacionista do labeling approach. Assim, a lei criminal faz seleção quantitativa (cifras negras como representação dos crimes não apurados ou sem solução); qualitativa (atuação dos costumes na falta e contra a lei na lei penal, antecipando sua mudança); e o processo formal de reação do sistema criminal adequa os fatos, os recria e conforma, e, assim,escolhe-se o crime e amoldase o fato.

Nesta adequação tenderão a ficar de fora da seleção do sistema penal aqueles que, estando classificados nos preconceitos e representações sociais da polícia, sociedade e órgãos de controle, melhor se apresentem como cidadão.

Ou seja, a pessoa enquadra-se em classificação de não-criminoso por via de maior status social, econômico, educacional, além de poder ter acesso a meios legais ou ilegais de asseguramento da exclusão da persecução penal como contratação de advogados influentes, conhecimento de pessoas que podem livrá-lo da persecução, ou mesmo pela apresentação da 
sua argumentação bem desenvolta de acordo com representações sociais de pessoa fora do enquadramento de criminoso.

Ao revés disso, estando estas circunstâncias ao seu desfavor, estando enquadrado dentro de grupo usualmente selecionado pelo sistema penal, com atitudes, comportamentos e aparência cujos preconceitos e representações sociais indiquem como fora dos padrões de boa conduta será mais facilmente integrado a uma persecução penal, assim como seu déficit educacional, argumentativo, econômico.

De sorte que, no que toca à seleção e seus mecanismos, os desfavorecidos estão mais representados nas estatísticas, por conta da atuação do órgãos estatais com base em estereótipos.

Prosseguindo com Dias e Andrade, no que tange aos “sistemas” da justiça penal, eles não são integrados, pensam e agem diferentemente. A burocratização leva a relações de poder e outros fins que não os de justiça, a exemplo da exigência de determinado número de casos julgados, de despachos, mas não de efetiva justiça.

Como exemplo de inadequação e paradoxo do discurso punitivo estatal, podemos citar a Polícia, analisada em estudo criminológico fecundo de Dias e Andrade (1997), a partir do qual traremos as inconsistências da sua atuação.

Desde já, fique consignado que seja a Polícia, sejam outras instâncias de atuação no ramo penal como Ministério Público ou Poder Judiciário, todas serão objeto de estudos e críticas em suas atuações. Não havendo, assim, capitis diminutio para as instituições policiais frente a outros órgãos do sistema criminal.

Os autores, então, baseados em estudos interacionistas, comentam a existência da discricionariedade real, a polícia como símbolo mais visível do sistema formal de controle, linha de frente da repressão penal, tem papel determinante no processo de seleção.

Ela age com maior discricionariedade (chamada "de fato" ou em "sentido sociológico"), sem presença dos demais atores processuais e em contato direto com leigos. Pode agir da estrita legalidade à admoestação ou simples apatia, num grande leque de opções. Com isso a Polícia toma a maior parte das decisões políticas.

Quanto aos crimes conhecidos, esclarecidos e processados: os crimes conhecidos em geral não decorrem de atitude pró-ativa, mas de reação, que leva em conta até características da denúncia, e são o limiar da criminalidade oficial. Crimes esclarecidos: poucos crimes chegam a ter autor descoberto, a depender dos tipos de crime. Quanto aos crimes processados: há divergência nos números, a polícia age de forma a entender crimes da sua maneira e cria sua política criminal, à margem ou contra a lei (DIAS e ANDRADE, 1997). 
É notório o atraso no Direito Penal no Brasil, pouco se tem em conta sua visão do sistema como um todo em andamento. Idem com relação a diferentes formas de resolução de conflitos penais a exemplo de direito penal de duas velocidades com Silva Sánchez ou, conforme Hassemer, direito de intervenção, de características sancionadoras (YACOBUCCI, 2010), contraordenações, minimalismo penal, abolição, ou a justiça restaurativa no Brasil, havendo experiências em inúmeros países com resultados satisfatórios conforme Santana (2010) e Sica (2007).

A crise no Direito Penal é ampla, política, ideológica e prática, ele é ineficiente, seletivo, custoso, deixa de ser direito da liberdade para ser da segurança, intervindo mais, com penas mais severas.

De forma extremamente realista e direta, a criminologia crítica critica o direito penal indicando que fora feito para proteger classe dominante, então ela não está em crise, funciona bem (SANTOS, 2008). Contudo, nossa Constituição Federal, desde seus princípios fundamentais, é contra esse tipo de prática, já que consagra valores e princípios de solidariedade, democracia, justiça, bem estar social e cidadania, com respeito à dignidade humana.

Outro ponto de importante análise é retórica da punição estatal, posto que a sanção no Estado se utiliza de discurso e retórica própria e característica. Assim, quanto à retórica da decisão, vê-se que as decisões em termo de punição não agradam a sociedade, aumentando a sensação de insegurança, corroborando o sentimento de injustiça social, além da ocorrência de falta de explicitação das premissas e não concordância com as premissas implicitamente consideradas.

Não é outro o entendimento de Zaffaroni (1991) ao asseverar que sistema penal pretende dispor de poder que não possui, ocultando o verdadeiro poder que exerce. Isto porque, se ele fosse agir em todo o planificado, deveria criminalizar provavelmente todas as pessoas, por diversas vezes, o que o leva a exercer seu poder com altíssimo grau de arbitrariedade seletiva dirigida a setores vulneráveis, por óbvio.

Não é possível que ainda seja defensável sistema penal que mostra ser um mero embuste societário, utilizando a verdade de seus efeitos e o respeito a direitos fundamentais apenas pontualmente, e a violência e mentira como estratégias de atuação corriqueira.

Ainda com aquele autor, afirmação de que órgãos dos sistemas penais latinoamericanos favorecem reiteração dos discursos criminológicos administrativos, do discurso jurídico-penal antiquado e acrítico. O discurso jurídico-penal da América Latina além de ser desconexo com a realidade, está ligado, assim como o discurso criminológico, a um 
positivismo-periculosista.

Pontua-se, ainda que esses discursos surgiram e se desenvolveram a partir de estudos racistas, e, mais para frente, etiológicos, que estudaram grupos criminosos a partir de suas origens raciais ou tendência para crime e periculosidade de certos sujeitos sociais.

Já estudo de Minahim (1997), percebe-se a atenção à incoerência e descolamento entre discurso jurídico posto e a realidade. É citado, apenas como demonstração de casos comuns, exemplo de mulher que foi condenada a mais de dois anos de prisão por haver furtado dois pacotes de fraldas e uma pessoa que cumpriu mais de cinco anos de reclusão por furto de galo de briga.

Ainda são citados os problemas da seletividade e criminalização secundária pelo Estado, bem como desproporcionalidade de penas, especialmente quando ligadas à proteção do patrimônio, além de altas taxas de reincidência após prisão, mesmo em locais de alta qualidade prisional como a Escandinávia.

Em Foucault (2012, p. 46-48), cita-se morte em presídio, que se declara como suicídio, comenta-se de juízes competentissimamente distraídos, administração do executivo e judiciário encobrindo verdades e fatos como mortes.

$\mathrm{Na}$ visão desse autor, as punições estatais suprimiram suplício por mudança de relações sociais e necessidade de poder mais presente, contínuo e modelador do homem, no entanto, a nova racionalidade gerou sistema que estabelece punições sem critérios de maior consideração à pessoa e para manter próprio sistema posto e, consequentemente, as próprias punições, daí a conclusão de Foucault que as infrações são estabelecidas para manter o próprio poder de punir e suas funções, como gestão de ilegalidades e distribuição diferencial de sanções.

Conclui-se que observações de Foucault (2012, p. 40) estão em grande parte corretas, e de fato "para o poder, o crime paga", pois longe de reformar, a prisão constitui delinquência como único meio de existência. O sistema capitalista diz lutar contra criminalidade e eliminála pelo sistema carcerário, que só produz mais criminalidade.

Mesmo com progressiva casca protetora da sociedade, que é a democracia, constituição e direitos humanos, ainda podemos visualizar pouca diferença para a situação trazida por Foucault. A título exemplificativo, para crimes como sonegação e fraude fiscal há extinção de punibilidade ao se quitar o débito, mas para crime como furto não há sequer possibilidade de transação penal.

Ademais, pode-se perceber plêiade de crimes de pouca importância, por vezes com pequenas penas de prisão ou mesmo com altas penas, especialmente os crimes contra 
patrimônio ou contra moral, seja ela familiar, religiosa ou sexual.

Com estudo apenas perfunctório sobre Código Penal, vêem as imensas desproporções e criminalizações excessivas, v.g.: a bigamia é punida com reclusão de dois a seis anos, já o abandono de incapaz com detenção de seis meses a três anos, e mesmo se resultar lesão corporal grave, a pena ainda é menor do que aquela, de um a cinco anos.

Poder-se-ia pensar que tais disparates seriam objetos de legislações ultrapassadas, em claro descompasso da dogmática penal com Estado Constitucional Democrático de Direito, respeito a direitos humanos e princípios constitucionais e produção científica penal e criminológica em estudos que nem recentes são.

Entrementes, mesmo hoje, notam-se as desconsiderações a toda crítica à falta de legitimidade do sistema penal e sua incompatibilidade constitucional e democrática, sua manutenção cega e alienada da realidade que ele próprio, sistema penal brasileiro, ocasiona.

Nada mais exemplar que a tentativa de manutenção desse mesmo sistema punitivo através de anteprojeto de novo código penal em tramitação (ANTEPROJETO DE CÓDIGO PENAL, 2012) que, ao largo de todas as críticas e demonstrações realizadas, mantém mesmas bases com mudanças pontuais e não estruturais, nova pintura e mesma fundação.

Esse novo e nada inovador projeto dispõe pena de um a quatro anos para omissão de socorro a animal, e pena de um a seis meses a omissão de socorro a criança abandonada, por exemplo, e ao resultar morte, varia entre três a dezoito meses.

A par da falta de sistematicidade com ausência de ponderação e proporcionalidade entre bens envolvidos, desconsideram-se todas as objeções e perigos demonstrados nas penas de prisão, acolhendo-a como grande referencial de punição.

A sociedade não está livre das malhas do poder e da economia do corpo, como Foucault bem estudou, porém o poder de transformar a sociedade em mais justa ou com mais atuação de direito humanos e respeito à constituição tem seu saber correlato e imbricações recíprocas. E é possível usá-lo e melhorar situação da economia do corpo ou até minorar seu simples domínio pelas estruturas de poder, através de implementação e abrangência de instrumentos diversificadores, por exemplo.

A utilização da prisão deve ser reservada como punição em última instância, quando não haja outra alternativa que demonstre resultado de integração ao ordenamento e confiança no direito e nos preceitos de justiça, com prevenção geral e específica positivas ou em último caso, negativas.

Contudo, ainda nos deparamos com crimes graves, facções criminosas, e outros atentados aos direitos fundamentais de indivíduos. 
De modo que não se pode abrir mão de coibir danos graves a esses direitos, e, eventualmente, para condutas gravíssimas, o maior rigor punitivo pode representar maior promoção de bem estar social e menor dano a direitos humanos, se houver perspectiva de resultado.

Todavia, há necessidade premente de reformá-la e enquadrá-la dentro de legalidade, integrando indivíduos e demonstrando a eles a confiança que podem ter no discurso punitivo estatal de rigor contra condutas graves e cumprimento da legalidade.

Ao mesmo tempo, a prisão deve ter capacidade de ser extremamente dura e impedir atuação no seu seio de comandos de facções criminosas, tráfico de drogas ou abusos físicos e psicológicos, como ocorre livremente hoje sob responsabilidade do Estado que mantém penitenciária.

Assim, haja vista que a punição é feita para ser desagradável e ocasionar representação de algo a evitar, não pode ela ser usada com desdém e abandono pelo Estado, com desvios de finalidade e forma de gerir ilegalismos.

Como visto, os ingredientes perversos do sistema penal se misturam de forma a minar a constituição de uma sociedade livre, justa e solidária, com promoção de bem comum e agredir os Direitos Fundamentais da coletividade e de cada um dos envolvidos em infrações penais, uma vez que nem protegem vítima e coletividade de agressões a bens jurídicos, muito menos é dada oportunidade de socialização e integração do preso à sociedade, uma vez que quaisquer dos regimes prisionais (aberto ou fechado) são locais onde são estimuladas condutas contrárias ao Direito (MATHIESEN, 1997) e percebe-se ausência completa do Estado (BATISTA, 2005).

O Poder Legislativo não diversifica (DIAS e ANDRADE, 1997) nem estrutura minimamente uma política criminal, a exemplo de reduções de tipos penais, respostas estatais diferenciadas de acordo com gravidade das infrações, além de irrisoriamente escalonar reações proporcionais e gradativas de controle social.

Por seu lado, o Executivo, que enfrenta os problemas práticos, não tem capacidade de reação em face das infrações em demasia, distorce o sistema penal com atuação repressiva e seus problemas reflexos, onde os envolvidos numa lide penal encaram a face mais dura do Estado que prega a igualdade, justiça, isonomia, respeito aos direitos humanos.

Os problemas de estigmatização, reincidência, seletividade penal, formalismo, legalidade processual estrita, criminalização secundária, custos a direitos fundamentais e custos econômicos não são exaustivos, ainda se pode acrescer o desrespeito a direitos humanos no cárcere, dificuldade argumentativa e desigualdade real do discurso no caso de 
réus menos educados e capacitados, além da qualidade dos defensores, entre muitos outros não levantados nessa breve exposição.

O Judiciário conta, na média, com excessivo rigor legalista na interpretação e aplicação do Direito na seara penal. Além de também somatizar problemas de seletividade e formalização das instâncias de sorte a marginalizar réus que usualmente têm déficits cognitivos e argumentativos.

Dessarte, a interpretação pouco permeável à realidade punitiva estatal e os problemas que ocasiona, com o argumento de se tratar o Direito Penal de um campo sensível à proteção da sociedade e de suas relações intersubjetivas, não passa de um pedaço do argumento completo.

Já que, justamente por se tratar de campo sensível às relações sociais e de defesa de todos e cada um dos indivíduos, deve ele ser mais detalhadamente estudado em seus fundamentos de legitimidade e de justiça, com aplicação de princípios e ampla consideração sobre as consequências das normas (MACCORMICK, 2008, p. 136) ${ }^{3}$.

Neste sentido é que dizemos que o procedimento judicial e doutrina do Direito Penal é excessivamente positivista. Deveria sim estar mais aberto a valores, princípios, interpretação e argumentação, análises consequencialistas e até econômicas dos princípios fundamentais da constituição e dos direitos fundamentais em jogo e como maximizá-los, bem como maximizar a utilidade da punição e minimizar seus efeitos deletérios.

Por outro lado, longe de pretender a aplicação e proteção dos Direitos Fundamentais apenas dos penalmente acusados e condenados, esses devem ser compreendidos para todos os envolvidos nas infrações, em regra, autor, vítima e coletividade.

Se assim não for, a visualização da punição estatal fica comprometida com uma visão puramente de defesa apenas da vítima e coletividade, por um lado, ou do autor, por outro. Tal parcialidade não se adequa aos fundamentos do Estado de Direito, Direitos Fundamentais e regras morais e normativas de universalização como formas de justiça.

As formas de interpretação e aplicação do Direito Penal, e a atuação dos Poderes tratados, têm que considerar sempre os Direitos Fundamentais de todos os envolvidos em determinada infração, uma vez que característica desses é a extensão de sua aplicabilidade a todas as pessoas humanas.

\footnotetext{
3 "Devemos dar atenção apenas à visão intermediária, de que alguns tipos e alguns conjuntos de
} consequências devem ser relevantes para a justificação de decisões” (MACCORMICK, 2008, p. 136). 


\section{A ESCOLHA DA ÉTICA E DE VALORES EM FACE DA FUNCIONALIDADE DO DIREITO}

Após todo o visto não se pode crer em ordenamento jurídico sem referência ética, a valores ou ao homem, mas apenas referenciado ao sistema em si. O que seria quase a existência de um ser divino, que somente se autorreferencia, está acima de todos, e se impõe sobre cidadãos sem consideração a estes individual ou coletivamente considerados.

Em critica a esse tipo de forma sistêmica de ordenamento jurídico, pode-se dizer que, em âmbito criminal, não mais se teria preocupação com prevenções, mas manutenção do sistema posto. E se ele é ilegitimo, o sistema se ocupará de manter a mesma estrutura ilegítima, sempre preocupado apenas com o próprio sistema (ZAFFARONI, 1991).

Dessa forma, a verdade se converte numa questão de funcionalidade. Todavia, o importante não é que qualquer sistema posto seja funcional, mas que seja funcional o sistema que seja legítimo, democrático, racional, protetor e promotor de uma sociedade igualitária e justa, com promoção de bem estar social, dignidade humana e direitos humanos e fundamentais. De sorte que, o funcionalismo sistêmico apoiaria qualquer forma de poder posto, mesmo que tirânico e opressor da pessoa.

O discurso relegitimante sistêmico criminal é fórmula perigosa para relegitimar sistema penal, uma vez que toma em consideração o sistema e não as pessoas. Dessarte, ele transfere a proteção para as estruturas já postas, que são protetoras das situações estabelecidas e conjunto de poderes atuantes.

Deve haver proteção da coletividade, considerada como pluralidade de pessoas, não proteção de um sistema vivo maior que todos e que se impõe sem nada considerar ou referenciar.

Nesse sentido, Brochado (2006, p. 61) critica normativismo jurídico, pois, em suas palavras, não é qualquer coisa que se pode validar formalmente na ordem jurídica, transformando pessoas, que são sujeitos de direito, apenas em sujeitos de deveres.

O direito é parte da ética ao formalizar conteúdo das "morais individuais em recíproca influência na totalidade social" (BROCHADO, 2006, p. 60). Ele se legitima como expressão da vontade popular, através de diálogo social. A passagem da consciência moral individual para a intersubjetiva vem por reconhecimento e, assim, o consenso objetiva as instituições sociais.

Ao elogiar dogmática jurídica como pilar da cultura ocidental, Adeodato expõe sua 
discordância com dogmatismo e falta de visão crítica: “o dogmatismo, estribado no legalismo exegético e na falta de visão crítica, entre outros fatores, tem-na levado a um perigoso distanciamento da realidade" (ADEODATO, 2009, p. 310).

O autor traz mau-exemplos ocasionados por esses equívocos: "São exemplos dessa teoria jurídica estéril e disfuncional postulados como o monopólio do direito por parte do Estado, a neutralidade da lei ou a imparcialidade do juiz" (ADEODATO, 2009, p. 310).

Esses três postulados são rechaçados aqui também quando da análise do discurso jurídico penal e da busca de legitimidade e eficácia do ordenamento, bem como pela busca de direito baseado em consenso social possível e informado, evitando-se manipulações do direito.

Entendendo o direito como produção societária e para agir nela, Bezerra (2010,p. 31) coloca-o em linha direta com realidade e questões sociais:

Em conexão com esse conteúdo justo, o direito, necessariamente, atentará para questões sociais que extrapolam do fenômeno jurídico em sentido estrito. Não existindo o direito senão pela sociedade, pode admitir-se que todos os fenômenos jurídicos são, pelo menos de certo modo, fenômenos sociais $[\ldots]$

o direito deve conter uma conexão necessária com o que chamamos de componente ético-social do direito.

Nesse raciocínio, o direito não está fora de contexto social, cultural e histórico da sociedade, nem é feito para aplicar-se em outra realidade que não a dela. Impossível concordar, desta feita, com um direito que não abrigue ou considere pessoas, sua individualidade e valores, e componente ético-social.

Pelo exposto, acreditamos que essa é a forma do direito adequada à nossa realidade constitucional e democrática, que permite considerações amplas e conforme princípios e valores, especialmente os constitucionais e democráticos.

Importa ressaltar que a depender do tipo de direito e de suas premissas poder-se-á manter e blindar relações de poder, efetuar manutenção de castas e privilégios e, assim, tentar legitimar amplas desigualdades e injustiças.

Acreditamos que tal tipo de ordenamento jurídico e de sua interpretação e aplicação, por mais que ainda tenha lugar e influência em imaginário de muitos que detém poder real, deve ser completamente sepultado.

Há de se concordar com Welzel (RADBRUCH, SCHMIDT e WELZEL, 1971), ao relatar que a legislação, sua recepção e sua ulterior elaboração na consciência jurídica, 
sobretudo doutrina e jurisprudência, estão todos sobre domínio da aspiração de encontrar uma ordem correta e justa no tempo.

De sorte que a produção do direito tem que encontrar recepção na consciência jurídica do povo, e esta consciência tem capacidade de formular o justo, havendo também considerações de minoria que devem ser ouvidas e levadas em conta para não absolutizar a consciência jurídica do povo e condenar minoria divergente.

\section{CONSIDERAÇÕES FINAIS}

Pelo exposto, assevera-se que através do Direito agem muitos outros fatores que não só ordenamento jurídico, mas interpretação da lei e de fatos, considerações axiológicas decorrentes de contexto social e nele atuantes, argumentação via forma retórica e via conteúdo material, seja especialmente jurídico, filosófico, social ou advindo de senso comum, seja referente a demais conhecimentos e informações relevantes.

Tais fatores extrínsecos ao direito, como visto, são realidades de alta importância para se chegar a uma solução justa, onde ultrapassa-se a racionalidade moderna como capaz de gizar completamente o conhecimento e estancar o jurídico a um pensamento que se pensa universal e imutável, quando a sociedade e o conhecimento são mutáveis e locais, tanto em paradigmas quanto em interesses e valores.

No campo penal onde muitos problemas de ordem jurídica são apresentados, tanto no campo judiciário quanto no de políticas criminais e de execução de suas medidas, o direito deve assumir posição consentânea com paradigma atual de construtor de soluções mais adequadas, mesmo que isso importe em intromissão em Executivo, Legislativo ou mesmo Judiciário, já que não reconhece Poderes ao largo e acima do povo, mas Deveres estatais que estão postos pelo povo e para o povo, na construção de uma sociedade justa, promotora de bem estar, que não importe em segregação, dominação ou exploração, ao modo dos princípios fundamentais elencados na nossa Constituição.

Destarte, não será intromissão do Judiciário corrigir inconstitucionalidades da lei ou de prática punitiva penal, adequá-los a princípios e valores estabelecidos na Lei Fundamental e efetivar dignidade da pessoa humana, ultrapassando meras construções legais cujas racionalidades não mais se coadunam com realidade ou nunca se coadunaram.

Para realização desse direito adequado, em última hipótese, no processo 
argumentativo e exposto a críticas, haverá controle de decisões pela via institucional recursal, a qual, não sendo bastante, legitimará e conclamará a via da censura e mobilização social, o que se espera e se deseja ao serem rompidas as defensas do direito e da justiça quando da imposição de decisões contrárias à ética e que sustentem desintegração social por uso da força punitiva estatal apenas para manutenção de status quo vigente e não para a construção de sociedade justa, solidária e que promova bem comum.

\section{REFERÊNCIAS:}

ADEODATO, João Maurício. Ética e retórica: para uma teoria da dogmática jurídica. São Paulo: Saraiva, 2009.

ANTEPROJETO DE CÓDIGO PENAL. Senado Federal, 2012. Disponível em: http://www.senado.gov.br/atividade/materia/getTexto.asp?t=111516\&c=PDF\&tp=1. Acesso em 14/01/2013.

BATISTA, Vera Malaguti. “A funcionalidade do processo de criminalização na gestão dos desequilíbrios gerados nas formações sociais do capitalismo pós-indústrial e globalizado", in KARAM, M. L. (org), Globalização, Sistema Penal e Ameaças ao Estado Democrático de Direito. Rio de Janeiro: Lumen Juris, 2005.

BEZERRA, Paulo César S. Sociologia jurídica. Rio de Janeiro: Renovar, 2010.

BROCHADO, Mariá. Direito e ética: a eticidade do fenômeno jurídico. São Paulo: Landy Editora, 2006.

DIAS, Jorge de Figueiredo; ANDRADE, Manuel da Costa. Criminologia - O Homem Delinqüente e a Sociedade Criminógena. Coimbra: Coimbra Editora, 1997.

FOUCAULT, Michel. Segurança, penalidade e prisão. Rio de Janeiro: Forense Universitária, 2012. 
. Vigiar e punir: nascimento da prisão. Petrópolis: Vozes, 1987.

GÜNTHER, Klaus. Teoria da argumentação no Direito e na moral: justificação e aplicação. Rio de janeiro: Forense, 2011.

MACCORMICK, Neil. Retórica e o Estado de Direito. Rio de Janeiro: Elsevier, 2008

MATHIESEN, Thomas e outros. "A caminho do Século XXI - Abolição, um sonho impossível?", in PASSETTI, E.; SILVA, R. B. D. da. Conversações abolicionistas. Uma crítica do sistema penal e da sociedade punitiva. São Paulo: IBCCRIM, 1997, vol IV, p. 263-287.

MINAHIM, Maria Auxiliadora. Inovações penais. Revista Jurídica dos Formandos em Direito da UFBA, Salvador, v.2, n.2 , p.77-86, jul./dez. 1997.

RADBRUCH, G., SCHMIDT, E., WELZEL, H. Derecho injusto y derecho nulo. Madrid: Aguilar, 1971.

SANTANA, Selma Pereira de. Justiça Restaurativa: A reparação como consequência jurídico-penal autônoma do delito. Rio de Janeiro: Lumen Juris, 2010.

SANTOS, Juarez Cirino dos. A Criminologia Radical. Curitiba: ICPC: Lumen Juris, 2008.

SICA, Leonardo. Justiça Restaurativa e Mediação Penal. O novo modelo de justiça criminal e de gestão do crime. Rio de Janeiro: Lumen Juris, 2007.

SOARES, Ricardo Maurício F. O discurso constitucional da dignidade da pessoa humana: uma proposta de concretização do direito justo no pós-positivismo brasileiro. Salvador: 2008. Tese (doutorado) UFBA.

YACOBUCCI, G. J. 2010. "Los Desafios del Nuevo Derecho Penal”, in Föpel, G. (org.). Novos Desafios do Direito Penal no Terceiro Milênio: Estudos em homenagem ao Prof Fernando Santana. Rio de Janeiro: Lumen Juris. 
ZAFFARONI, Eugenio Raul. Em busca das penas perdidas: a perda de legitimidade do sistema penal. Rio de Janeiro: Revan, 1991. 